\title{
Correlation between Initiating Time of Mobilization and Cardio Pulmonary Stability among Critical Ill
} Patient

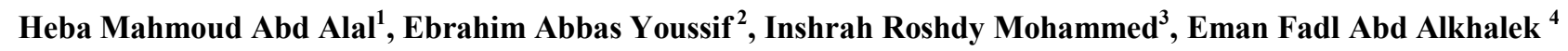

\author{
${ }^{1}$ Bachelor of nursing Faculty of Nursing, Minia University; \\ ${ }^{2}$ Prof\& Founder of Anesthesia and Intensive Care Department, Faculty of Medicine - Minia University; \\ ${ }^{3}$ Assistant Prof of Medical Surgical Nursing Department, Faculty of Nursing -Minia University; \\ ${ }^{4}$ Lecturer of Medical Surgical Nursing Department, Faculty of Nursing -Minia University
}

\begin{abstract}
Background: the mobility and exercise play an important role in the recovery of functional status, early mobilization of critically ill patients who are admitted to intensive care units. This should be performed based on safety criteria that were categorized as follows: cardiovascular, respiratory, neurological, in addition rehabilitation of critical ill patients depends on various factors, such as previous physical strength and functioning, level of cooperation, and devices connected. The Aim of the current study is to assess correlation between initiating time of mobilization and cardiopulmonary stability among critical ill patients. Design: A descriptive research design was utilized in the current study. Subjects of this study are consecutive purposive sample who are admitted in previous intensive care units at Minia University and who are related to inclusion criteria. Setting: the study was carried out at two critical care units (traumatic intensive care unit and neurosurgery care unit). Tools: two tools were developed by the researcher, the first tool is Patients' structured questionnaire (personnel characteristics, patient's medical information data) and the Second tool is patient's cardiopulmonary assessment sheet, and one standardized scale (Perm scale). Results: showed that most of mobility practice (93.3\%) were not done by I C U nursing staff except only two practices which were done for most of the studied sample (91.7\%) as to move into standing position and to use walker or assistive device respectively and it was revealed that majority percentage for potential mobility barriers among study's sample who had pain constituted (93.3\%). Conclusion: the early mobility for critical ill patients after admission in intensive care unit was a rapid effect on selected cardiopulmonary instability parameters and improvement on patients out comes. Recommendation: conscious patients and nurses should be educated about early mobility exercise; Post admission to intensive care unit had a positive effect on muscle strength and cardiopulmonary stability.
\end{abstract}

Keywords: Initiating time of mobilization, Cardiopulmonary Stability, Critical Ill Patient

\section{Introduction}

Critical illness is a life-threatening multisystem process that can result in significant morbidity or mortality. In most patients, critical illness is preceded by a period of physiological deterioration, such as frequently missing of accurate recording and documentation for vital signs, recognition and interpretation of abnormal values, patient assessment, appropriate intervention and early-warning systems are an important part that can help in identifying patients at risk of deterioration and serious adverse events ${ }^{(1)}$.

An intensive care unit (ICU), or critical care unit (CCU), is a special department of a hospital that provides intensive treatment medicine, close observation and monitoring for seriously ill patients who are at high risk of complications and monitors, intravenous (IV) tubes, feeding tubes, catheters, breathing machines, and other equipment which are common in critical care units .Approximately $20 \%$ of acute care admissions are to an intensive care unit while up to $58 \%$ patients are from emergency department admissions such as Cardiac, respiratory and neurologic disorder which are common in adult ICU patients ${ }^{(2.3 .4)}$

Prolonged immobilization of critically ill patients has negative repercussions on the musculoskeletal, cardiovascular and respiratory systems, the skin and cognition. To prevent and minimize such effects, immediate physical therapy intervention is necessary, provided the patient exhibits the clinical stability needed to meet the vascular and oxygen demands posed by this type of intervention ${ }^{(5)}$.

Immobilization effects on hemostasis process which are increase in blood viscosity, reduction in plasma volume and decrease in oxygen demand because of muscle atrophy as well as a hemostatic in balance between pro and anti$P$ a g e $\mid 26$ coagulator factors which can lead to pathological formation of thrombus and also bed rest immobilization that affect on lungs which reduce their forced vital capacity as well as bronchociliar activity which increase the risk of respiratory infections ${ }^{(6)}$.

Early mobilization refers to initiating physical exercise or mobilization within the early illness phase which is an increasingly common practice in intensive care units (ICU). This proves to be feasible and safe in preventing bed-restassociated morbidity, while improving patients' physical function psychological condition, and quality of life. Mobilizing patients at an early time point has been associated with reduced health care costs, delirium and hospital length of stay. And improve patient outcomes. So early mobilization should be performed within the first $24 \mathrm{~h}$ of ICU admission (7.8)

Early mobility (within $48 \mathrm{~h}$ of admission) with a mobility team improved patient outcomes and increased the frequency of physical therapy in ICU patients. Daily activity progressed through basis of consciousness of patients and increased strength, starting with passive range-of-motion exercises, sitting on the edge of the bed, transfers from bed to chair, and ambulation. The results of mobility there were no adverse events, such as removal of tubes or devices and decrease ICU LOS ${ }^{(9)}$.

\section{Significance of the Study}

The early mobilization can safely occur within two to four days of admission in critically ill patients particularly those requiring mechanical ventilation (MV), who are prone to impairments in physical function associated with immobility and intensive care unit (ICU) acquired weakness. Functional

Heba M., et al 
impairments acquired during ICU hospitalization result in increased need for long term nursing care, greater risk of readmissions and reductions in health-related quality of life for ICU. ${ }^{(10)}$. (Li Z, Peng and zhub 2013)

It Has been observed by the researcher over a period of one year from 2015 in intensive care units in Minia university that the critical ill patients complain from complication from lack in their mobilization, so this current study assesses correlation between initiating time of mobilization and cardiopulmonary stability among critical ill patients .

\section{Operational definition initiating time of mobilization for critical ill patients.}

The concept of mobilization of critically ill patients is energy consuming and consists of physical and psychological aspects, including activities that produce movement such as "active limbs exercising, actively moving in bed, sitting on the edge of the bed, etc.. Mobilization also is defined as "the physical activity that, is performed with the appropriate intensity, produces physiological benefits for the organism", acting on the circulation, central and peripheral perfusion, ventilation, or state of consciousness. The term "early" refers to activities that are carried out from the initial physiological stabilization that continues during the ICU stay. ${ }^{(11,12)}$

The effects of early rehabilitation on patients who survive their disease at the ICU, focuses on interventions aimed at preventing the (Intensive Care Unit Acquired Weakness) ICUAW, which also improves physical capacity. $\left({ }^{13,14)}\right.$

\section{Aim of the study}

The aim of the present study was to assess correlation between initiating time of mobilization and cardiopulmonary stability among critical ill patients.

\section{Research question}

Are there correlations between initiating time of mobilization and cardiopulmonary stability among critical ill patients?

\section{Subject and Method \\ Study design}

The descriptive correlated research design was utilized in this study.

\section{Study Subjects}

Consecutive purposive sample who are admitted in previous intensive care units at Minia University and who are related to inclusion criteria participated in this study.

\section{Study Setting}

This study was carried out at two critical care units(traumatic intensive care unit and neurosurgery care unit at Minia university hospital the traumatic I C U is located on the second flour in the building called ( $G$ ) with 8 beds which involved thirteen nurses . the neurosurgery care unit is located in second flour in the building called ( A ) with 8 beds and involved eleven nurses .

\section{Inclusion criteria}

- Adult (less than 65) patient male and female patients.

- Recent critical ill patients who were admitted to I C $\mathrm{U}$
- full conscious and oriented patient

- Post operative patient admitted to I C U

\section{Exclusion criteria}

- The patient who has pelvic, long bone fracture or skeletal traction

- Patient who has facial trauma or known difficult breathing

- Patients with spinal or cranial injuries associated with abnormal intracranial pressure.

\section{Tools of data collection}

Two tools were designed and used for data collection, these tools were formulated by the researcher after revising extensive relevant literature review and one standardized scale.

First tool: Patients' interview structured questionnaire. It covered two main parts:

- Part 1: personal characteristics this included (age, gender,$\ldots \ldots \ldots \ldots \ldots \ldots$...ect)

- Part 11 : patients medical information data which included : (past chronic illness, chief complaint, weight, duration of bed rest, initiating time of mobility ,...............ect )

Second tool: patient's cardiopulmonary assessment sheet that includes:

- Measuring pulmonary parameters as : respiratory (rate, rhythm and depth), oxygen saturation, chest sound...........$e c t$ before and after mobility practices within 15 minutes .

- Measuring cardio parameters as : pulse (rate, rhythm , strength ), blood pressure , .................ect before and after mobility practices within 15 minutes

Perm scale

This scale was adapted from perm (2009) ${ }^{(15)}$ used to evaluate level of studied subjects mobility practice by the researcher's observation and included three categories as (bed mobility, transfers and gait)

\section{System score:}

The entire above category is performed by the participants in the study from the first day to third day from admission to intensive care units until the patients discharge. It is ranked into done completely which scored by (1) and not done scored by (0).

- $\quad<85 \%$ is considered unsatisfactory performance (who did practices from less than (6/9)

- $85 \%$ is considered satisfactory performance from $(7 / 9)$

\section{Tools validity:}

Content validity was done to identify the degree to which the used tools measure what was supposed to be measured. the developed tools were examined by a panel of three experts in the field of medical surgical nursing department and medical staff who are related to critically ill specialty in \{ Minia university - faculty of nursing\}. All jury members $(100 \%)$ agreed that the current study tools were valid and relevant to the aim of the study. 


\section{Tools reliability:}

Tools reliability was done to identify the extent of consistency of the tools items with the study concept and their correlation with each other, and intraclass correlation coefficient by cronbacks test at baseline $0.9 \%$.

\section{Pilot study:}

A pilot study was carried out on $10 \%(n=6$ patients $)$ from total study sample to test feasibility, objectivity, and applicability of the data collection tools. Carrying out the pilot study gave the investigator the experience to deal with the included subjects and to be familiar with the data collection tools. Based on the results of the pilot study, no modification or refinement were done and the subjects were included to the actual sample

\section{Ethical consideration:}

An official permission to conduct the study was obtained from the ethical committee in the faculty of nursing, Dean of nursing faculty, and the manager of Minia university hospital, the head of each unit's critical, neurosurgery care unit, and agreement from Egypt academy for research center and technology. Subjects participated in this study voluntarily and each involved subject gone oral consent to participate as was told information about the purpose, benefits, and nature of the study and that he /she had the right to withdraw from the study at any time without any rational. Confidentiality and anonymity of each subject were ensured through coding of all data and protecting the obtained data. Subjects were informed that the obtained data will not be included at any further researches without a second oral consent.

\section{Study Procedure:}

The current study was conducted by preparing different data collection tools, in addition to, obtaining oral and paper agreement which were taken in a duration of one week before conducting the study . the researcher collected the current study data from its setting on daily basis (3-4 days / weeks ) at least two patients weekly according to inclusion criteria during morning or afternoon shifts .

The researcher started data collection from the studied participant in the study by using the first and second tools (patients' structure questionnaire, physical and cardiopulmonary assessment sheet) and observation for third tools (perme scale) within 6-8 months at the start of the study.

The researcher observed that mobility practice was done every mid time shift starting patients mobility (three times / day) and The researchers assessed and follow up the studied participants for mobilization within three day from admission and their cardiopulmonary stability

On the other time of , the researcher trained the inters students who had shift in the same study setting to observe the study participant in accurate time during specific work shift and assist the researcher in assessment of their cardiopulmonary status using the second tools, and perm scale .

\section{Statistical analysis of data:}

Data were summarized, tabulated, and presented using descriptive statistics in form of frequency distribution , percentages, means and the standard deviation as a measure by dispersion .a statistical package for the social science (SPSS) version (20) 2017 was used for statistical analysis of data, as it contains the test of significance given in standard statistical books . Numerical data were expressed as mean and SD. Qualitative data were expressed as frequency and percentage. Probability ( $p$ - value) is the degree of significance, less than 0.05 was considered significant, the smaller ( $\mathrm{p}$ - value ) obtained. The more significant is the result $(*)$, less than 0.001 was considered highly significant $(* *)$ and correlation coefficient was done by using pearson Brown's correlation test

\section{Results}

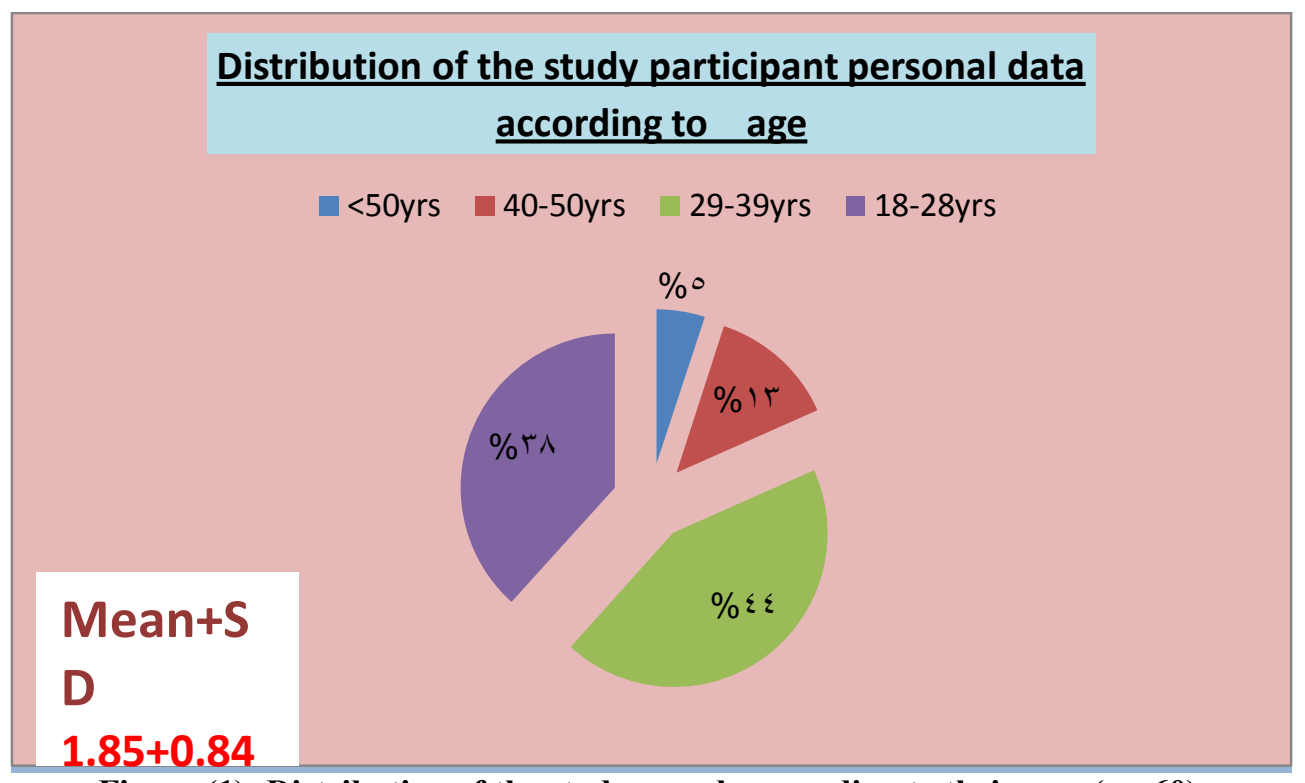

Figure (1): Distribution of the study sample according to their age $(n=60)$. 


\section{Distribution of the study participant personal data according to gender}
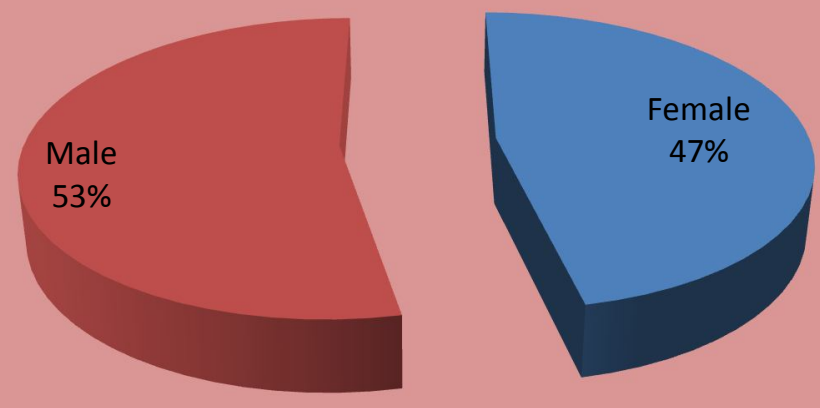

Figure (2): Distribution of the study sample regarding to their gender(n=60).

Figures $(1 \&$ 2) show that, the highest percentage of studied samples age ranged between (29 to 39 years), with Mean $+\mathrm{SD}=$ $1.85+0.840$ and more than fifty percent among them were males $(53 \%)$

Table (1): Frequency distribution by percentage of the study samples regarding to other medical data $(n=60)$

\begin{tabular}{|c|c|c|c|}
\hline \multirow{2}{*}{ Other medical data } & \multicolumn{2}{|c|}{$\mathrm{N}=60$} & \multirow{2}{*}{ Mean+ SD } \\
\hline & $\mathbf{N}$ & $\%$ & \\
\hline \multicolumn{4}{|l|}{ Previous admission } \\
\hline Yes & 14 & 23.7 & \multirow{2}{*}{$1.77+0.42$} \\
\hline No & 46 & 76.7 & \\
\hline \multicolumn{4}{|l|}{ Duration of bed rest } \\
\hline$-\quad 3$ days & 29 & 48.3 & \multirow{3}{*}{$1.52+0.50$} \\
\hline 4 days & - & - & \\
\hline 5 days & 31 & 51.7 & \\
\hline \multicolumn{4}{|l|}{ Patient's position changed } \\
\hline$-\quad$ Every $2 \mathrm{hrs}$ & & & \multirow{4}{*}{$2.40+0.61$} \\
\hline Every work shift & 40 & 66.7 & \\
\hline Every day & 16 & 26.7 & \\
\hline$-\quad$ Not done & 4 & 6.7 & \\
\hline \multicolumn{4}{|l|}{ Initiation time of mobility } \\
\hline$-\quad 1$ day & - & - & \multirow{5}{*}{$1.60+0.55$} \\
\hline 2 day & - & - & \\
\hline 3 day & 26 & 43.3 & \\
\hline 4 day & 32 & 53.3 & \\
\hline 5 day & 2 & 3.3 & \\
\hline
\end{tabular}

Table (1) reveals that, the three quarter among the studied participants did not have previous admission to I C U (76.7\%) with mean $1.77+0.42$ and more than half among them stayed in I C U five days $(51.7 \%)$ with mean $1.52+0.50$. Concerning to change position among studied participant results showed that (66.7) with mean $2.40+0.61$ changed their position by staff nurses every shift and they initiated mobility practice for them in the fourth day from admission.

Table (2): Frequency distribution by percentage for study sample's to assess their mobility level by using Perm mobility observation checklist scale $(n=60)$

\begin{tabular}{|c|c|c|c|c|}
\hline \multirow{2}{*}{ Mobility practice } & \multicolumn{4}{|c|}{ Perm mobility observation } \\
\hline & Done $>70$ & $\%$ & Not done $<70$ & $\%$ \\
\hline \multicolumn{5}{|l|}{ 1)Bed mobility } \\
\hline 1- Change position from supine or semi recumbent then sitting position every 2 hours & 9 & 15 & 51 & 85 \\
\hline 2- Assist the patient during change position & - & - & 60 & 100 \\
\hline 3- Ask the patient verbally to change his position & 4 & 6.7 & 56 & 93.3 \\
\hline 4-Assess the level of assistance once the patient assume his position change & & - & 60 & 100 \\
\hline \multicolumn{5}{|l|}{ 2)Transfer } \\
\hline 1- Move patients on side of bed or chair & - & - & 60 & 100 \\
\hline 2- Move patients into the standing position & 52 & 86.7 & 8 & 13.3 \\
\hline $\begin{array}{l}\text { 3- When patient was already out of the bed and did not return to bed the activity should } \\
\text { be scored }\end{array}$ & - & - & 60 & 100 \\
\hline \multicolumn{5}{|l|}{ 3) Gait } \\
\hline 1-the complete gait cycle is completed several times & 43 & 71.7 & 17 & 28.3 \\
\hline 2-use walker or other assistive device & 49 & 91.7 & 11 & 18.3 \\
\hline
\end{tabular}

Table (2) shows that most of mobility practice were not done by I C U nursing staff except only two practices which were done for studied sample as to move into standing position and to use walker or assistive device constituted (86.7 \% \& $91.7 \%)$ 
Minia Scientific Nursing Journal (Print) (ISSN 2537-012X) Vol. (6) No. (1) December 2019

respectively implemented by staff nurses , on the other hand, the majority percentage among studied sample had not performed mobility practices in bed which were provided from their I C U nursing staff constituted ( $85 \% \& 100 \% \& 93.3 \%)$ while the minority percentage was found only in transfer constituted (13.3\%).

Table (3): Correlation of respiratory characteristics among study sample through selected parameters before and after mobility $(n=60)$

\begin{tabular}{|c|c|c|c|c|c|c|c|c|c|c|c|c|c|c|c|c|}
\hline Mobility practice & \multicolumn{7}{|c|}{ Respiratory rate Before initiating mobility } & \multicolumn{7}{|c|}{ Respiratory rate After initiating mobility } & $\mathbf{T}$ & $\bar{P}$ \\
\hline During sitting in bed & 60 & & $\begin{array}{l}\% \\
100\end{array}$ & - & & - & & 60 & 10( & & - & & - & & \multirow[t]{2}{*}{1.21} & \multirow{2}{*}{$\begin{array}{l}0.23 \\
\mathrm{NS} \\
\end{array}$} \\
\hline Mean+ SD & \multicolumn{7}{|c|}{$19.8+3.06$} & \multicolumn{7}{|c|}{$23.3+22.1$} & & \\
\hline During sitting in chair & \multicolumn{3}{|c|}{60} & \multicolumn{2}{|l|}{-} & \multicolumn{2}{|l|}{-} & 60 & \multicolumn{2}{|c|}{100} & \multicolumn{2}{|l|}{-} & - & & 3.34 & $\begin{array}{l}0.000^{*} \\
*\end{array}$ \\
\hline During ambulation & 60 & 10 & 00 & - & & - & & 60 & 100 & & - & & - & & \multirow[t]{2}{*}{14.2} & $0.000 *$ \\
\hline Mean+ SD & \multicolumn{7}{|c|}{$19.3+1.22$} & \multicolumn{7}{|c|}{$21.4+1.43$} & & \\
\hline & \multicolumn{7}{|c|}{ Respiratory rhythm Before initiating mobility } & \multicolumn{7}{|c|}{ Respiratory rhythm After initiating mobility } & $\mathbf{T}$ & $\mathbf{P}$ \\
\hline Mobility practice & Regular & $\%$ & & Irregu & & $\%$ & & Regular & $\%$ & & Irreg & & $\%$ & & & \\
\hline Mean+ SD & $1.10+0.3$ & & & & & & & $1.10+0.3$ & & & & & & & & \\
\hline During Sitting In Chair & 55 & & 1.7 & 5 & & 8. & & 60 & 100 & & - & & - & & $2.3^{`} 1$ & $0.024 *$ \\
\hline Mean+ SD & $1.08+0.2$ & & & & & & & $1.00+0.0$ & & & & & & & & \\
\hline During Ambulation & 60 & 10 & 00 & - & & - & & 59 & 98. & & 1 & & 1. & & 1.01 & 0.321 \\
\hline Mean+ SD & $1.00+0.0$ & & & & & & & $1.02+0.1$ & & & & & & & & NS \\
\hline Mobility practice & Respirat & tory de & epth Befor & initiati & mo & ilit & & Respirat & y de & h After & itiatin & ob & & & $\mathbf{T}$ & $\mathbf{P}$ \\
\hline & \begin{tabular}{l|l} 
Norm \\
al
\end{tabular} & $\%$ & \begin{tabular}{|l|l|} 
Shallo \\
$\mathbf{w}$
\end{tabular} & $\%$ & & & $\%$ & $\begin{array}{l}\text { Norm } \\
\text { al }\end{array}$ & $\%$ & $\begin{array}{l}\text { Shallo } \\
\text { w }\end{array}$ & $\%$ & & & $\%$ & & \\
\hline Mean+ SD & $1.08+0.3$ & & & & & & & $1.00+0.0$ & & & & & & & & \\
\hline During Ambulation & \begin{tabular}{l|l}
60 \\
\end{tabular} & 100 & - & - & - & & - & 59 & 8.3 & 1 & 1.7 & - & & - & 1.00 & 0.32 \\
\hline Mean+ SD & $1.00+0.0$ & & & & & & & $1.02+0.1$ & & & & & & & & NS \\
\hline
\end{tabular}

$* \mathbf{p} \leq 0.05$ (significant) T-test: $\mathrm{P}-$ value based on independent sample t-test, F-test $\mathrm{P}-\mathrm{Value}$ based on compares mean $\mathbf{N S}=\mathrm{No}$ Significant difference * Statistical significant difference

Table (3) reveals that there were significant differences in assessment of respiratory characteristics (rate \& rhythm and depth) among studied sample before and after initiating mobility for them as sitting in chair respectively. While only respiratory rate had significant differences among studied sample before and after initiating mobility for them as ambulation.

Table (4) Correlation of selected cardiac parameters ( blood pressure, peripheral edema and capillary refill ) for studied sample before and after initiating mobility practices $(n=60)$

\begin{tabular}{|c|c|c|c|c|c|c|c|c|c|c|}
\hline \multirow[b]{2}{*}{ Mobility practice } & \multicolumn{4}{|c|}{ Blood pressure Before initiating mobility } & \multicolumn{4}{|c|}{ Blood pressure After initiating mobility } & \multirow[t]{2}{*}{$\mathbf{T}$} & \multirow[t]{2}{*}{$\mathbf{P}$} \\
\hline & Normal & $\%$ & $\begin{array}{l}\text { Abnorma } \\
\text { l }\end{array}$ & $\%$ & Normal & $\%$ & $\begin{array}{l}\text { Abnorma } \\
\text { l }\end{array}$ & $\%$ & & \\
\hline During Sitting In Bed & 45 & 75 & 15 & 25 & 45 & 75 & 15 & 25 & \multirow[t]{2}{*}{0} & \multirow[t]{2}{*}{0} \\
\hline Mean+ SD & \multicolumn{4}{|c|}{$1.25+0.43$} & \multicolumn{4}{|c|}{$1.25+0.43$} & & \\
\hline During Sitting In Chair & 49 & 81.7 & 11 & 18.3 & 53 & 88.3 & 7 & 11.7 & \multirow[t]{2}{*}{2.05} & \multirow[t]{2}{*}{$0.045^{*}$} \\
\hline Mean+ SD & \multicolumn{4}{|c|}{$1.18+0.39$} & \multicolumn{4}{|c|}{$1.12+0.32$} & & \\
\hline During Ambulation & 54 & 90 & 6 & 10 & 54 & 90 & 6 & 10 & \multirow[t]{2}{*}{0} & \multirow[t]{2}{*}{0} \\
\hline Mean+ SD & \multicolumn{4}{|c|}{$1.10+0.30$} & \multicolumn{4}{|c|}{$1.10+0.30$} & & \\
\hline \multirow[b]{2}{*}{ Mobility practice } & \multicolumn{4}{|c|}{ Peripheral edema Before initiating mobility } & \multicolumn{4}{|c|}{ Peripheral edema After initiating mobility } & \multirow[t]{2}{*}{$\mathbf{T}$} & \multirow[t]{2}{*}{$\mathbf{P}$} \\
\hline & Yes & $\%$ & No & $\%$ & Yes & $\%$ & No & $\%$ & & \\
\hline During Sitting In Bed & 8 & 13.3 & 52 & 86.7 & 8 & 13.3 & 52 & 86.7 & \multirow[t]{2}{*}{0} & \multirow[t]{2}{*}{0} \\
\hline Mean+ SD & \multicolumn{4}{|c|}{$1.87+0.34$} & \multicolumn{4}{|c|}{$1.87+0.34$} & & \\
\hline During Sitting In Chair & 8 & 13.3 & 52 & 86.7 & 5 & 8.3 & 55 & 91.7 & \multirow[t]{2}{*}{1.76} & \multirow[t]{2}{*}{$0.083^{*}$} \\
\hline Mean+ SD & \multicolumn{4}{|c|}{$1.87+0.34$} & \multicolumn{4}{|c|}{$1.92+0.27$} & & \\
\hline During Ambulation & 4 & 6.7 & 56 & 93.3 & 4 & 6.7 & 56 & 93.3 & 0 & 0 \\
\hline Mean+ SD & \multicolumn{4}{|c|}{$1.93+0.25$} & \multicolumn{4}{|c|}{$1.93+0.25$} & & \\
\hline & Capillar & fill $\mathrm{Be}$ & tiating mob & & Capillar & fill Af & ating mobil & & $\mathbf{T}$ & $\mathbf{P}$ \\
\hline Mobility practice & Normal & $\%$ & $\begin{array}{l}\text { Prolonge } \\
\text { d more } \\
\text { than } 3 \text { sec }\end{array}$ & $\%$ & Normal & $\%$ & \begin{tabular}{lr}
\multicolumn{2}{l}{ Prolonge } \\
d $\quad$ more \\
than 3 \\
sec
\end{tabular} & $\%$ & & \\
\hline During Sitting In Bed & 50 & 83.3 & 10 & 16.7 & 51 & 85 & 9 & 15 & 1.00 & $0.32 *$ \\
\hline Mean+ SD & $1.17+0.3$ & & & & $1.15+0.3$ & & & & & \\
\hline During Sitting In Chair & 57 & 95 & 3 & 5 & 59 & 98.3 & 1 & 1.7 & 1.42 & $0.15^{*}$ \\
\hline Mean+ SD & $1.05 \_0.2$ & & & & $1.02+1.2$ & & & & & \\
\hline During Ambulation & 59 & 98.3 & 1 & 1.7 & 59 & 98.3 & 1 & 1.7 & 0 & 0 \\
\hline Mean+ SD & $1.02+1.2$ & & & & $1.02+1.2$ & & & & & \\
\hline
\end{tabular}

$* \mathrm{p} \leq 0.05$ (significant) T-test: $\mathrm{P}-$ value based on independent sample t-test, F-test $\mathrm{P}-\mathrm{Value}$ based on compares mean NS= No Significant difference * Statistical significant difference

Table (4) shows that there is significant correlation between initiating mobility practices and normal blood pressure \& no presence of peripheral edema among studied participants when they are sitting in bed $(\mathrm{P}=0.045 \& \mathrm{P}=0.083)$ respectively but table 
findings mentioned that there were correlation between normal capillary refill for studied group when they are sitting in bed and during sitting in chair $(p=0.32 \& p=0.15)$ respectively.

Table (5): The correlation between means among cardiopulmonary parameters after initiating mobility practices.

\begin{tabular}{|c|c|c|c|c|c|}
\hline Variable & \multicolumn{3}{|c|}{ Pulmonary data } & \multirow{2}{*}{$\begin{array}{l}\mathbf{X}^{\mathbf{2}} \\
13.00\end{array}$} & \multirow{2}{*}{$\begin{array}{l}\mathbf{P} \\
.002^{* *}\end{array}$} \\
\hline Dyspnea & $1.87+0.34$ & $1.97+0.18$ & $2.00+0.000$ & & \\
\hline Respiratory rate & $23.35+2.17$ & $20.80+3.31$ & $21.45+1.43$ & 18.67 & $.000 * *$ \\
\hline Respiratory rhythm & $1.10+0.30$ & $1.00+0.000$ & $1.02+0.129$ & 8.85 & $.012 *$ \\
\hline Respiratory depth & $1.15+0.40$ & $1.00+0.000$ & $1.02+0.129$ & 12.66 & $.002 *$ \\
\hline Chest sound & $1.40+0.66$ & $1.13+0.43$ & $1.08+0.33$ & 24.57 & $.000^{*}$ \\
\hline Cyanosis & Sit in bed & $2.00+0.00$ & $2.00+0.00$ & 12.00 & $.002 *$ \\
\hline \multicolumn{6}{|c|}{ Cardio assessment data } \\
\hline Pulse rate & $92.30+6.81$ & $94.08+11.08$ & $95.12+9.71$ & 13.66 & $.001 * *$ \\
\hline Pulse rhythm & $1.03+0.181$ & $1.03+0.181$ & $1.03+0.181$ & 0 & 0 \\
\hline Pulse depth & $1.07+0.252$ & $1.05+.220$ & $1.07+.252$ & 1.00 & .607 \\
\hline Blood pressure & $1.25+0.437$ & $1.12+0.324$ & $1.10+0.303$ & 16.22 & $.000^{* *}$ \\
\hline Edema & $1.87+0.434$ & $1.92+0.279$ & $1.93+0.252$ & 6.50 & $.039^{*}$ \\
\hline Capillary refill & $1.15+0.360$ & $1.02+0.129$ & $1.02+0.129$ & 16.00 & $.000^{* *}$ \\
\hline
\end{tabular}

Table (11) reveals that there statistical significant correlation between mobility practice and all cardiopulmonary parameters among studied sample except pulse (rhythm \& depth $)(p=0 \& p=0.607)$ respectively

\section{Discussion}

Section I: personal data of the studied sample:

The present study revealed that, study sample's age ranged between (29 to 39 ) with mean $1.85+0.840$ years respectively. This is related to highest percentage of study sample's chief complaint which was hemodynamic unstable after motor car accident when admitted in I $\mathrm{c} u$, the number of car accidents which occurred in Eygpt in 2017 recorded 11,098 incidents, declining by 24.6 percent .

This result agreed with Chlan et al., 2015 ${ }^{(16)}$ who mentioned that age range of the subjects in I c u was 23- to 93 -years. And $56 \%$ of the studies had more male than female subjects. in the same line the current study finding is in accordance with Strandberg et al., $\left(\mathbf{2 0 1 3}^{(17)}\right)$ who illustrated that distribution of age between study sample in I c u was (18 -35 ) years with mean .0164 ,

The results of the present study revealed that the majority of the study sample were males. The statistical analysis of the data obtained showed that they were in middle age who had occupation responsibilities and drive or use vehicles more than other people. This result agreed with Chlan et al., $2015^{(16)}$ who mentioned that $56 \%$ of the studies had more male than female subjects.

An other finding is in dis agreement with Fisher et al., (2010) (18) who mentioned that during the pre implementation period from mobilization program patients in the ICU had an average mean age of 67.0 (15.7) years; $42 \%$ were females, also the patients followed in the ICU post implementation mobilization program had an average age of 64.4 (17.0) years of age; $48 \%$ were females .

\section{Section II: Medical data of studied sample:}

On the other hand, Most of the studied sample who admitted to I $\mathrm{c} \mathrm{u}$ with a changing their position every shift with average mean $2.40+0.61$ this related to shortage in nursing staff . This result is dis agree with (Castro et al., 2015) ${ }^{(19)}$ that had shown when patients are mobilized early within their admission to the ICU, patient outcomes improved and the length of stay in the ICU were reduced.

Also in the same line, Doherty-King et al., (2014) (20) mentioned that increasing mobilization of patients had done more work for nurses to mobilize their patients during their shift/work day for rehabilitation therapists and are mobilized at least once daily by nurses and rehabilitation therapists receiving more training on how to safely mobilize their patients .

Section (III) describes assessment of study sample's potential mobility barriers \& perm mobility observation to study sample mobility.

The present study revealed that most of study sample passively transfer from bed to standing position then gait this may be related to patient's cardiopulmonary stability. This result agreed with Mehrholz et al., (2015) ${ }^{(21)}$ who found that patients transfer from bed to chair and initiate gait training, Joint mobilization, range of motion, (rolling, sitting up) sitting and rising from a chair, independent standing and then ambulation that permitted up to 20 min of cycling focused on improving mobility and progression of functional mobility training .

In the same line the result is congruent with Schweickert, 2009 , Burtin, 2009 ${ }^{(22.23)}$ who found that Critically ill patients can exercise, sit up, transfer to bedside chairs, and ambulate, and monitored programs of physical activity this can lead to statistically significant improvements in ambulation independence, ability to perform self care activities, and improved respiratory function.

Section IV: is concerned with the effect of early mobility on cardiopulmonary stability before and after mobility among studied sample.

The finding is congruent with Hodgson et al., (2014) and Garzon-Serrano et al., (2011) ${ }^{(24.25)}$ who aimed to observe and maintain blood pressure, heart rate, and oxygen saturations within reasonable limits which are required to evaluate this after mobility and also put recommendations on safety criteria to consider before embarking on active mobilization of critically ill patients.

In other researches supported by Morris et al., (2008) and Hodgson et al., (2014), ${ }^{(26.27)}$ there were no deaths, near-deaths, or cardiopulmonary resuscitation during physical therapy and there were no adverse events, such as removal of tubes or devices and monitoring is critically important, and this must be performed by personal trained to know how to respond as ( heart rate, pulse oximeter, ventilator settings, blood pressure, and alertness/agitation) in 
patients who must be carefully monitored during any mobility procedure.

Also researches done by Castillo et al., (2008) and Santhanam R, et al (2007) ${ }^{(28.29)}$ are validated with the current study which mentioned that during various body positions how to improve oxygenation $\mathrm{SpO} 2$ value and (PR, $\mathrm{RR}$, and BP) was maintained at acceptable level (hemodynamically stable) in each position, and it showed increase in the following sequence; supine, right-side, leftside, and sitting. However, improvement was noted in $\mathrm{SpO}_{2}$ only in sitting position.

Section V: is concerned with correlation between selective personal data for studied sample and cardiopulmonary parameters with regard to mobility practices (sitting in bed, sitting in chair and ambulation )

The current study illustrated that there is strong positive correlation between cardiopulmonary parameters and mean average gender among study sample. Because most of the study sample were in middle adulthood and were males which increases the tolerance of pain to initiated mobility practice. In addition, most of them had haemodynamic unstable. This led to rapid improvement when participating in mobility practice.

This result is supported by the study which agreed with Titsworth et al., (2012) ${ }^{(30)}$ who mentioned that most patient's characteristics were not associated with highest mobility level, except that mobility was lower in women. In the same line the study is consistent with Smith et al., (2011) and De Feo et al., al (2012) ${ }^{(31.32)}$ who demonstrated a lower women's access to cardiac rehabilitation than men and also an important difference in their clinical profile and management

Moreover, the finding is compatible with the researches carried out by C. L. Dobrovolny et al., (2003) and M. J. MacKay-Lyons and L. Makrides (2002) ${ }^{(33)}$ who found that cardiopulmonary is important for performing daily activities and mobility, the majority of the studies dealt with men.

\section{Conclusion:}

The early mobility for critical ill patients after admission in intensive care unit had a rapid effect on selected cardiopulmonary instability parameters and improvement on patient's outcomes.

\section{Recommendation:}

Educating conscious patients and nurse about early mobility exercise post admission to intensive care unit had a positive effect on muscle strength and cardiopulmonary stability.

\section{References}

1) ROBERTSON, Laura C.; AL-HADDAD, Mohammed. Recognizing the critically ill patient. Anaesthesia \& Intensive Care Medicine, 2013, 14.1: 11-14.

2) BARRETT, Michael L., et al. Utilization of intensive care services, 2011: Statistical Brief\# 185. 2006.

3) SMITH, S. E. (2013-03-24). Bronwyn Harris (ed.). "What is an ICU". wiseGEEK. Sparks, Nevada: Conjecture Corporation. Retrieved 2012-06-15.

4) WUNSCH, Hannah, et al. ICU occupancy and mechanical ventilator use in the United States. Critical care medicine, 2013, 41.12.
5) PARRY, Selina M.; PUTHUCHEARY, Zudin A. The impact of extended bed rest on the musculoskeletal system in the critical care environment. Extreme physiology \& medicine, 2015, 4.1: 16.

6) BLOCH, Susannah, et al. Molecular mechanisms of intensive care unit-acquired weakness. 2012.

7) WEBER-CARSTENS, Steffen, et al. Critical illness myopathy and GLUT4: significance of insulin and muscle contraction. American journal of respiratory and critical care medicine, 2013, 187.4: 387-396.

8) HAKKENNES, Sharon; LINDNER, Christopher; REID, Jodie. Implementing an inpatient rehabilitation Saturday service is associated with improved patient outcomes and facilitates patient flow across the health care continuum. Disability and rehabilitation, 2015, 37.8: 721-727.

9) TEAM STUDY INVESTIGATORS, et al. Early mobilization and recovery in mechanically ventilated patients in the ICU: a bi-national, multi-centre, prospective cohort study. Critical Care, 2015, 19.1: 81.

10) LI, Zhiqiang, et al. Active mobilization for mechanically ventilated patients: a systematic review. Archives of physical medicine and rehabilitation, 2013, 94.3: 551-561.

11) CASTRO-Avila Ac, Serón P, Fan E, et al. : Effect of early rehabilitation during intensive care unit stay on functional status: systematic review and metaanalysis. PLoS One, 2015, 10: e0130722.

12) STILLER K: Physiotherapy in intensive care: an updated systematic review. Chest, 2013, 144: 825847.

13) Hermans G, De Jonghe B, Bruyninckx F, et al. : Interventions for preventing critical illness polyneuropathy and critical illness myopathy. Cochrane Database Syst Rev, 2014, (1): CD006832.

14) CALVO-AYALA E, Khan BA, Farber MO, et al.: Interventions to improve the physical function of ICU survivors: a systematic review. Chest, 2013, 144: 1469-1480.

15) PERME, Christiane; CHANDRASHEKAR, Rohini. Early mobility and walking program for patients in intensive care units: creating a standard of care. American Journal of Critical Care, 2009, 18.3: 212-221.

16) CHLAN, Linda L., et al. Peripheral muscle strength and correlates of muscle weakness in patients receiving mechanical ventilation. American Journal of Critical Care, 2015, 24.6: e91-e98.

17) STRANDBERG, Timo E., et al. The "obesity paradox," frailty, disability, and mortality in older men: a prospective, longitudinal cohort study. American journal of epidemiology, 2013, 178.9: 1452-1460.

18) FISHER, Steve R., et al. Early ambulation and length of stay in older adults hospitalized for acute illness. Archives of internal medicine, 2010, 170.21: 1942-1943.

19) CASTRO, Emily, et al. Early mobilization: changing the mindset. Critical care nurse, 2015, 35.4: e1-e6.

20) DOHERTY-KING, Barbara, et al. Frequency and duration of nursing care related to older patient 
mobility. Journal of Nursing Scholarship, 2014, 46.1: 20-27.

21) MEHRHOLZ, Jan, et al. First results about recovery of walking function in patients with intensive care unit-acquired muscle weakness from the General Weakness Syndrome Therapy (GymNAST) cohort study. BMJ open, 2015, 5.12: e008828.

22) SCHWEICKERT, William D., et al. Early physical and occupational therapy in mechanically ventilated, critically ill patients: a randomised controlled trial. The Lancet, 2009, 373.9678: 1874-1882.

23) BURTIN, Chris, et al. Early exercise in critically ill patients enhances short-term functional recovery. Critical care medicine, 2009, 37.9: 24992505.

24) HODGSON, Carol L., et al. Expert consensus and recommendations on safety criteria for active mobilization of mechanically ventilated critically ill adults. Critical care, 2014, 18.6: 658.

25) Garzon-Serrano, J., Ryan, C., Waak, K., Hirschberg, R., Tully, S., Bittner, E. A., ... \& Zafonte, R. (2011). Early mobilization in critically ill patients: patients' mobilization level depends on health care provider's profession. PM\&R, 3(4), 307-313.

26) MORRIS, Peter E., et al. Early intensive care unit mobility therapy in the treatment of acute respiratory failure. Critical care medicine, 2008, 36.8: 22382243.

27) CASTILLO, Armando, et al. Pulse oxygen saturation levels and arterial oxygen tension values in newborns receiving oxygen therapy in the neonatal intensive care unit: is $85 \%$ to $93 \%$ an acceptable range?. Pediatrics, 2008, 121.5: 882-889.
28) SANTHANAM, R., et al. Intensive care management of head injury patients without routine intracranial pressure monitoring. Neurology India, 2007, 55.4: 349.

29) Titsworth, W. L., Hester, J., Correia, T., Reed, R., Guin, P., Archibald, L., ... \& Mocco, J. (2012). The effect of increased mobility on morbidity in the neurointensive care unit. Journal of neurosurgery, 116(6), 1379-1388.

30) SMITH, Sidney C., et al. AHA/ACCF secondary prevention and risk reduction therapy for patients with coronary and other atherosclerotic vascular disease: 2011 update: a guideline from the American Heart Association and American College of Cardiology Foundation endorsed by the World Heart Federation and the Preventive Cardiovascular Nurses Association. Journal of the American college of cardiology, 2011, 58.23: 2432-2446.

31) DE FEO, Stefania, et al. Gender differences in cardiac rehabilitation programs from the Italian survey on cardiac rehabilitation (ISYDE2008). International journal of cardiology, 2012, 160.2: 133-139.

32) DOBROVOLNY, C. Lynne, et al. Reliability of treadmill exercise testing in older patients with chronic hemiparetic stroke. Archives of physical medicine and rehabilitation, 2003, 84.9: 1308-1312.

33) MACKAY-LYONS, Marilyn J.; MAKRIDES, Lydia. Exercise capacity early after stroke. Archives of physical medicine and rehabilitation, 2002, 83.12: 1697-1702 